\title{
SPONTANEOUS CSF OTORRHOEA: REVIEW OF LITERATURE
}

\author{
N. Venkat Ram Reddy ${ }^{1}$, A. V. S. Hanumantha Rao², G. Raghunadh Babu ${ }^{3}$, T. Shankar ${ }^{4}$, S. Ramakrishna ${ }^{5}$
}

\section{HOW TO CITE THIS ARTICLE:}

N. Venkat Ram Reddy, A. V. S. Hanumantha Rao, G. Raghunadh Babu, T. Shankar, S. Ramakrishn. "Spontaneous CSF Otorrhoea: Review of Literature". Journal of Evolution of Medical and Dental Sciences 2015; Vol. 4, Issue 44, June 01; Page: 7679-7683, DOI: 10.14260/jemds/2015/1115

ABSTRACT: Spontaneous Leak of Cerebrospinal fluid (CSF) into the middle ear cavity can occur in adults without a history of temporal bone trauma or fracture, meningitis or any obvious cause, it may result from a number of congenital deformities of the ear. Mondini deformity an abnormal development of the cochlea is frequently associated with CSF leakage therefore clues may be lacking that would alert the otolaryngologist that fluid medial to an intact ear drum are fluid emanating from an ear drum perforation is likely to be CSF fluid. Here we are presenting a case of spontaneous CSF leaks in two sites and treated with surgical closure with cartilage graft.

KEYWORDS: Cerebrospinal fluid, temporal bone, Spontaneous, Mondini deformity, Meningitis.

INTRODUCTION: Spontaneous cerebrospinal fluid otorrhoea or temporal CSF leakage represents a difficult and serious condition to deal with, in terms of its diagnosis, especially with intact ear drum, management and its sequelae if not treated or diagnosed. CSF middle ear effusion/otorrhoea can develop in adults without history of meningitis or head trauma or any apparent proximate cause. Any clear pulsating fluid through myringotomy should arise the suspicion of CSF otorrhoea and encephalocele. Although presenting symptoms can be subtle, early suspicion of confirmatory imaging aid in establishing the diagnosis, Galbarriatu and others, $(1,2,3)$ it can be associated with or without skull base $\operatorname{defect}^{(4)}$, in the other hand spontaneous CSF otorrhoea is a rare entity, ${ }^{(4)}$ CSF leakage can trickle down through the eustachian tube more details to be presented as CSF oto-rhinorrhoea or nasal discharge. Any clear pulsating fluid through myringotomy should arise the suspicion of CSF otorrhoea and encephalocele which is a protrusion of intracranial contents can include brain matter and meninges through a defect in the cranium or skull base.(5)

CASE REPORT: A 29 years female patient, presented with complaint of watery discharge from (L) ear since 03 months, which was developed spontaneous, continuous, non-foul smelling, profuse not associated with URTI, no history of trauma, ear surgery, hearing loss, ear pain, patient was admitted for evaluation and treatment. All the investigations done, routine investigations are normal, CT scan of cisternography confirms CSF otorrhoea.

\section{HRCT Scan:}

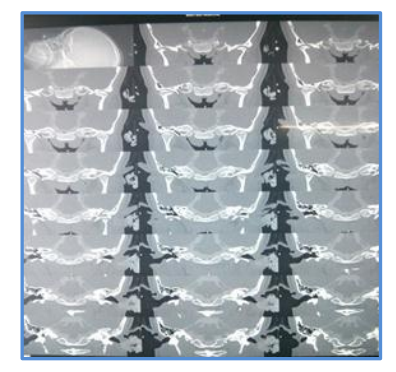

Fig. 1: HRCT PHOTO 
Report: (L) Mastoid, air cells and middle ear show soft tissue lesion with erosion of mastoid.

\section{CT Scan of Cisternography:}

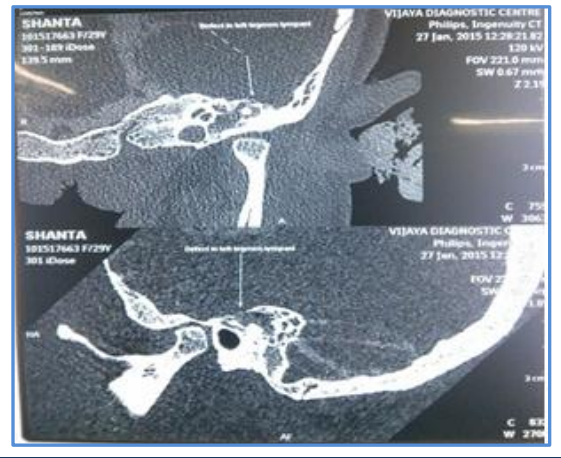

\section{Fig. 2: Photo of Cisternography}

Report: Soft tissue opacification envolving (L) middle ear cavity and mastoid air cells with focal erosion of tegmen tympani. A small defect of $3 \mathrm{~mm}$ size in the anterior aspect of tegmen tympani with contrast leak in to left middle ear cavity and mastoid air cells with opacification of cotton swab kept in left external ear - Findings are suggestive of CSF otorrhoea.

\section{CSF for Biochemical Analysis:}

Sugar - Hexokinase - $69 \mathrm{mg} / \mathrm{dl}$.

Proteins - Pyragallol red $-37 \mathrm{mg} / \mathrm{dl}$.

Cytopathology Report - Inflammatory cells present negative for a typical cells.

Diagnosis made as (L) CSF otorrhoea and posted for repair through transmastoid approach under general anaesthesia.

OPERATIVE FINDINGS: Mastoid cavity with clear air cells, CSF leak was identified from two sites, first site in the tegmen tympani in the roof of the antrum, the second leak from the posterio - inferior wall of mastoid cavity below the sigmoid sinus, both the defects were closed with double layered cartilage graft, supported by free muscle graft, temporalis fascia and gelfoam, mastoid cavity filled with medicated pack wound was closed in layers, ASD done post op CSF leak was completely stopped, patient is under follow up at the time of presenting this paper.

\section{Intra operative CSF leak site:}

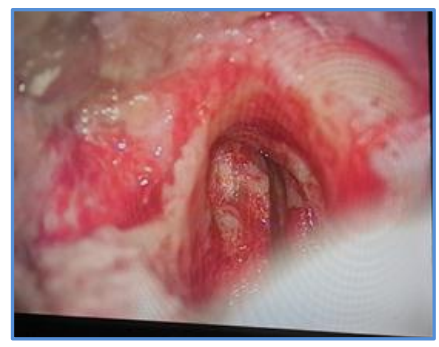

Fig. 3 


\section{CSF Leak sites after closure:}

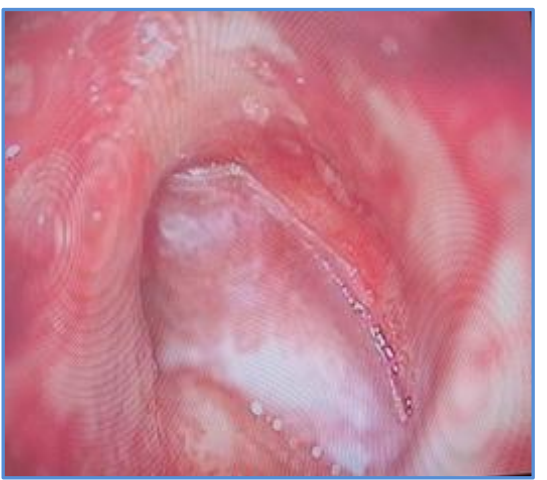

Fig. 4: First site closure

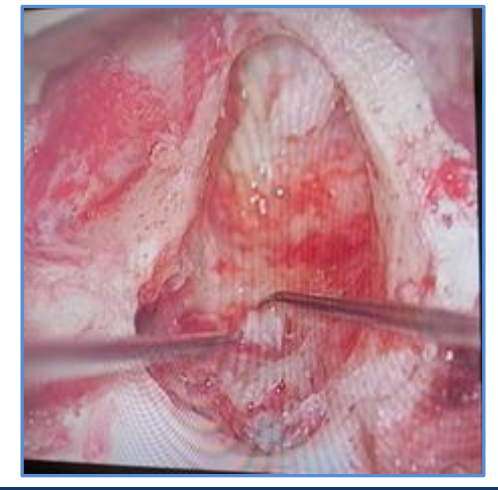

Fig. 4: Second site closure

DISCUSSION: CSF otorrrhoea the discharge of CSF from the ear, a rare, potentially life threatening situation that requires rapid intervention to present meningitis, linked to an abnormal communication between the sterile subarachnoid space with sino nasal tract flora. The most common site of CSF leakage is through the floor of the anterior fossa, which communicate with the ethmoid or frontal sinuses or with the nasal fossa, the sphenoid sinus is rarely implicated as a source of spontaneous CSF fistula communication with the middle cranial fossa. CSF fistula is more likely if the sphenoid, is laterally pneumatized.(6) The majority of patients presents with symptoms of aural fullness, middle ear effusion, hearing loss and for certain extent with headache and meningitis. Some patients had multiple defects in the tegmen and dura, and some can have meningoencephaloceles, can be seen behind the tympanic membrane. CSF pressures and the hydrostatic pulsative forces may lead to the development of pit holes on the middle fossa at the sites of arachnoid villi with herniation of dura/arachnoid or brain tissue. If such defects are located over the underlying well pneumatized middle ear, encephalocele can develop and lead to CSF leakage into the affected site. Therefore, erosion of bone by arachnoid granulations is only significant when it affects a pneumatized part of the skull.(7)

Laboratory testing of nasal or aural fluid drainage or aspirate for the presence of the protein Beta (beta)-2 transferring plays a key role in establishing the presence of a CSF leak. Such assays are not always available, making imaging pivotal in the diagnosis of this entity. The development of minimally invasive endoscopic repair further underscores the importance of imaging as precise anatomic localization is important for repair.(8) Both, computer tomography (CT Scan) and magnetic resonance image (MRI) play an important role for the diagnosis. The high resolution CT scan with fine cuts ( $1 \mathrm{~mm}$ or less) can shows the direct anatomy and the relationship in different parts of temporal bone and can give indirect evidence of the CSF fistulae by revealing bony defects and opacification of middle ear or mastoid air cells. As a role, if there is a bony defect at base of skull with fluid in the dependent area or sinus then CSF leakage should be rolled out. Magnetic resonance cisternography in particular can non-invasively reveal CSF leakage in multiple planes without the disadvantage of ionizing radiation. On the T2-weighted spin-echo image sequence, is a superior to other modalities, the bright signal from the CSF column is well visualized against the middle ear cleft or sinus background of air( ${ }^{(9)}$. MRI is essential to confirm the nature and extension of the lesion and 
any associated abnormalities. MRI is able to provide multiplanner images of the encephalocele that is useful for both diagnosis and surgical planning.

There are two well-known surgical approaches, the middle fossa craniotomy and the transmastoid approach. The management require adherence to the principles of establishing a safe ear as a primary goal, then with hearing restoration as a secondary goal.(10) As it is difficult in its presentation, the planning to repair it is also difficult with the middle fossa craniotomy provides the best exposure for defects involving the middle fossa floor but not all neuro-otologist or the neurosurgeons are familiar with it. Surgical repair is mandatory to seal those non-traumatic CSF leaks. A multi -layered closure technique in which autologous and artificial materials are combined is considered to result in the highest rate of success, the most common defect sites were located over the tegmen mastoideum and tegmen tympani. Multiple materials were used in most repairs including allogenic bone cement and autologous materials. Transmastoid approach in the other hand with fascia, cartilage, and fibrin glue is more popular to otologist and it is easy to visualized the defect from the roof of middle ear. Kari et al. demonstrated in his large group study in management of 56 consecutive patients with mastoid encephaloceles and CSF leaks. The majority were managed through the transmastoid route with temporalis fascia and calvarial bone graft. Among the patients operated on at least 18 months before analysis, there was a median follow - up of 54 months with no intracranial complications.(12) The imaging evaluation has evolved over the past several decades. Description of current techniques available to direct treatment options, including multi-detector thin section computed tomography, and imaging recommendations are presented. Because surgical repair by way of a mastoid approach alone can be inadequate if there are multiple tegmen defects, a middle fossa approach alone, or in combination with a transmastoid approach, should be considered in such cases.

CONCLUSION: Recognition of CSF otorrhoea can be difficult and challenging as the complication can be devastating serious, repairing the defect is mandatory to prevent these complication, for otologist transmastoid approach can be considered a good approach for repairing. Except if there are multiple defects where middle cranial fossa approach will be adequate. But in our case the two defects was closed successfully by transmastoid approach.

\section{REFERENCES:}

1. Galbarriatu L, Aurrecoechea J, Ruiz,de Gopegui E, Pomposo I, Bilbao G, Gonzalez S, et al. Adult spontaneous cerebrospinal fluid otorrhea. Report of two cases and review of the literature. Neurocirugia (Astur) 2011; 22: 150-6.

2. Connor SE. Imaging of skull-Base cephalocoeles and cerebrospinal fluid leaks. Clin Radiol 2010, 65: 832-41.

3. Kari E, Mattox DE. Transtemporal management of temporal bone encephaloceles and CSF leaks: Review of 56 consecutive patients. Acta Otolaryngol 2011; 131:391-4, Epub 2011 Feb. 11.

4. Brown NE, Grundfast KM, Jabre A, Megerian CA, O'Malley BW Jr, Rosenberg Sl. Diagnosis and management of spontaneous cerebrospinal fluid-middle ear effusion and otorrhea. Laryngoscope 2004: 114: 800-5.

5. Lloyd KM, Delgaudio JM, Hudgins PA. Imagining of skull base cerebrospinal fluid leaks in adults. Radiology 2008: 248: 725-36. 
6. Shetty PG, Shroff MM, Fatterpekar FM, Sahani DV, Kirtane MV. A retrospective analysis of spontaneous sphenoid sinus fistula: MR and CT findings. AJNR Am J Neuroadiol 2000; 21: $337-$ 42.

7. Schuknecht B, Simmen D, Briner HR, Holzmann D. Nontraumatic skull base defects with spontaneous CSF.

8. Bullock R. Soares D. Current imaging of cerebrospinal fluid leaks. West Indian Med J 2009: 58: 362-6.

9. Shetty PG, Shroff MM, Sahani DV. Evaluation of high-resolution CT and MR cisternography in the diagnosis of cerebrospinal fluid fistula. AJNR Am J Neuroradiol 1998; 19: 633-9.

10. Wootten CT, Kaylie DM, Warren FM, Jackson CG. Management of brain herniation and cerebrospinal fluid leak in revision chronic ear surgery. Laryngoscope 2005; 115: 1256-61.

11. Kutz JW Jr. Husain IA, Isaacson B, Roland PS. Management of spontaneous cerebrospinal fluid otorrhea. Laryngoscope 2008: 118: 2195-9.

12. Stenzel M. Preuss S, Orloff L. Jecker P, Mann W. Cererbrospinal fluid leakd of temporal bone origin: Etiology and management. ORL J Otorhinolaryngol Relat Spec 2005; 67: 51-5. Epub 2005 Mar 7.

\section{AUTHORS: \\ 1. N. Venkat Ram Reddy \\ 2. A. V. S. Hanumantha Rao \\ 3. G. Raghunadh Babu \\ 4. T. Shankar \\ 5. S. Ramakrishna}

\section{PARTICULARS OF CONTRIBUTORS:}

1. Associate Professor, Department of ENT, Osmania Medical College.

2. Professor, Department of ENT, Kakatiya Medical College, Warangal.

3. Professor, Department of ENT, Andhra Medical College, Vizag.

FINANCIAL OR OTHER

COMPETING INTERESTS: None
4. Professor, Department of ENT. Osmania Medical College.

5. Professor \& HOD, Department of ENT, Osmania Medical College.

\section{NAME ADDRESS EMAIL ID OF THE} CORRESPONDING AUTHOR:

Dr. T. Shankar, H. No. 12-5-149/6/A, Flat No. 201, Sajjas Ambuiance, Vijayapuri Colony, Tarnaka, Hyderabad - 17, Telangana.

E-mail: drshankar_ms@yahoo.com

Date of Submission: 07/05/2015. Date of Peer Review: 08/05/2015. Date of Acceptance: 23/05/2015. Date of Publishing: 30/05/2015. 